\title{
A Study on Consumer's Preferences according to the Role of Gift Giving
}

\author{
Yoon-hee Kang, \\ (Doctoral Student, Department of Psychology, Chung-Ang University) \\ Key Words: gift giving, regulatory mode, product type
}

\section{Introduction}

Gift behavior plays an important role not only in maintaining interpersonal relationships but also in managing corporate customer, such as giving gifts or rewards in loyalty programs.

Everyone who presents giver wants to be satisfied with the gift he chooses and to value it highly. Unfortunately, the person receiving the gift is usually tend to think their value is lower than the cost of purchasing a gift(Waldfogel, 1993).

This is because the giver and receiver look at the target(gift) from a different perspective. When evaluating the product, the mindset to activate has an important effect on the consumer's decision.

Thus, depending on which motivations and representations are activated, the same information can be treated differently and the final emotion and judgment may vary(Johar, Maheswaran, \& Peracchio, 2006; Brendl, Markman, \& Messner, 2001). This study verifies that the motivation for evaluating alternatives, and the preferences of the product may vary, depending on the role of gift giving.

A person giving a gift goes through a thought process that compares and analyzes many alternatives before acting for the purpose of purchasing a gift. Thus, they focus on the overall value, compares alternatives based on the ultimate utility. On the other hand, because the recipient of the gift is evaluated with the alternatives already decided, he focuses on the use of this product. Therefore, the study assumed that the regulatory mode would vary depending on the role of the gift giving.

\section{Study 1}

In study 1 , we observed differences in regulatory mode and the preference for product type(single dominant utility/multiple utility product) depending on the roles of gift giving for the same cost product.

Method: Participants were randomly divided into two conditions of gift giving(giver vs receiver) and were asked to assume the situation of giving or receiving gifts. Then, they measured the regulatory modes and chose the preference for the given gifts. Although the gift type is the same cost, it is presented differently depending on whether it is a predominant single utility or multiple utilities.

Results: As a result of the study 1, it was confirmed that the person who gives the gift has a higher level of the assessment regulatory mode, and the person who receives the gift has relatively higher the locomotion regulatory mode $(\mathrm{t}=7.91, \mathrm{p}<.01)$. In addition, a person who gives a gift has a higher preference for products with various multiple utilities than a predominant single utility. On the other hand, the recipient of the gift showed higher value perception and choice for the dominant single utility $\left(\mathrm{x}^{2}=19.65, \mathrm{p}<.01\right)$.

\section{Study 2}

In study 2, among the various utilities, preference differences were identified for alternatives highlighted with specific attributes.

Method: The scenario is similar to study 1, but study 2 has differentiated emphasis on the attributes of the gifts in the selection situation. More specifically, after assuming the situation of gifts giving or receiving, participants were asked to choose between products with different attributes of the gifts.

Results: As a result, the participants who assumed the role of giving chose the desirable alternatives. On the other hand, participants who assumed the role of receiving chose the alternatives that are easy to act on $\left(\mathrm{x}^{2}=5.80, \mathrm{p}<.05\right)$.

\section{Discussion}

The study revealed that the motivation to evaluate is different according to the role of gift giving. Furthermore, it has been showed that the role of gift giving can alter preferred gifts. These results have practical implications on what gift recipients can be satisfied with and how it is effective to organize a gift set in the corporation. 